\title{
SOBRE LA RESPONSABILIDAD PENAL DE LAS PERSONAS JURÍDICAS Y SU INCIDENCIA EN COLOMBIA
}

Daniel Tolosa Russi*

Resumen: En un mundo globalizado, la criminalidad de empresa ha crecido de una forma excepcional, creando nuevos desafíos para que el Derecho penal pueda proteger bienes jurídicos de nuevas formas de lesión, provenientes de nuevos actores del mundo social. Esto ha llevado a que en el Derecho comparado se encuentran varios ejemplos en los cuales las personas jurídicas son consideradas como capaces de responder penalmente. Es por esto que resulta pertinente realizar un análisis teórico y práctico sobre la creación de un Derecho penal para las empresas en nuestro ordenamiento jurídico nacional. En el presente artículo encontraremos respuesta a criterios dogmáticos sobre los cuales se fundamenta, desde una visión colombiana, la necesidad de implantar una responsabilidad penal de las personas jurídicas. También hallaremos aspectos sobre su capacidad de acción y su capacidad de culpabilidad. Al final se presentará una propuesta que contenga los parámetros más generales, sobre los cuales proponer una consagración legal en el Derecho positivo.

* Abogado, de la Universidad Externado de Colombia. Asesor jurídico de la Secretaría Académica de la Facultad de Derecho de la Universidad Nacional de Colombia. Correo-e: dftolosar@unal.edu.co. Bogotá, Colombia. Fecha de recepción: 30 de junio de 2015. Fecha de modificación: 6 de julio de 2015. Fecha de aprobación: 30 de julio de 2015. Para citar el artículo: DANIEL Tolosa Russi (2015). "Sobre la responsabilidad penal de las personas jurídicas y su incidencia en Colombia", Revista Derecho Penal y Criminología, Vol. 36, $\mathrm{n}^{\circ}$. 100, enero-junio de 2015. Bogotá: Universidad Externado de Colombia, pp. 13-43. DOI: http://dx.doi.org/10.18601/01210483.v36n100.02 
Palabras clave: Responsabilidad penal; Personas jurídicas; Derecho Penal económico; Criminalidad de empresa; Capacidad de acción; Capacidad de culpabilidad.

\title{
ABOUT THE CRIMINAL RESPONSIBILITY OF LEGAL PERSONS AND ITS INFLUENCE IN COLOMBIA
}

\begin{abstract}
In a globalized world, corporate crime has been increasing exceptionally. This has created new challenges for the criminal law to protect legal rights from many new risks. This increase in corporate crime has made it possible that corporations can be prosecuted under the criminal system in some countries. It is because of that we must consider it important to analyze the possibility of creating a Criminal Law System for corporations in our legal system. In this article we offer answers about the base over which we can create a corporate crime system, from a Colombian perspective. Also, we will found out some aspects about the actions taken by corporations and their culpability. At the end we will present a short proposal that contains general aspects over which we hope to develop a Positive Law.
\end{abstract}

Keywords: Criminal Responsibility; Corporations; Economic Criminal Law; Corporate Crime; Action; Culpability.

\section{INTRODUCCIÓN}

La importancia que han adquirido las personas jurídicas a través de todas sus formas empresariales en esta nueva realidad social, en donde ya no se entiende una economía, una industria o una actividad financiera sin que estas hagan parte de la misma, ha generado discusiones no solo académicas sino también políticas y gubernamentales. Está bastante claro que la forma como se participaba en la vida económica cambió de manera drástica, al mutar de las relaciones estrictamente personales hacia las relaciones empresariales, en las que el sujeto individual ya no es imprescindible sino que, por el contrario, puede ser cambiado sin que se afecte realmente la relación comercial y económica.

Este fenómeno socioeconómico ha traído como consecuencia el advenimiento de una nueva forma de criminalidad que, por sus especiales características, debe ser valorada y analizada con detenimiento. Dicha forma de criminalidad es la denominada "Criminalidad de empresa". En esta ya no se trata de los tradicionales problemas de delincuencia organizada que partían de una idea grupal plenamente ilegal sino que sus acciones, problemas y características parten de criterios diametralmente opuestos. La criminalidad de empresa es aquella que se funda en una persona jurídica legítimamente constituida, pero cuyas acciones, que en principio son consideradas 
legales, se desvían hacía la lesión de bienes jurídicos colectivos o, incluso, aquellos netamente individuales o personales.

Con miras a esta nueva realidad criminal, cuyas especiales repercusiones requieren de una política clara y eficaz que la detenga, es que se ha propuesto rebatir o, a lo sumo, replantear el tradicional principio penal de societas delinquuere non potest. Ya se han visto casos en los cuales las categorías dogmáticas tradicionales se presentan insuficientes y los sistemas clásicos de establecimiento de responsables no dan abasto. En muchas ocasiones, las vicisitudes en la toma de decisiones al interior de una empresa, en donde la posesión de la información, la toma de la decisión y la ejecución material del hecho recaen sobre personas completamente diferentes que pueden no solo llegar a no conocerse sino que, incluso, pueden vivir en diferentes ciudades, países o continentes, terminan por generar un espectro de impunidad y hacen que las empresas, que son las verdaderas beneficiarias del resultado del delito, salgan impunes después de haber realizado la lesión al bien jurídico en una desviación de sus actividades.

Ahora, si bien la idea de tener un Derecho penal para las empresas es algo que ha existido durante mucho tiempo en los países de tradición anglosajona, en los cuales es posible imponerle una pena con todas sus características a los entes colectivos luego de cumplir un procedimiento de investigación criminal, en los países de tradición europea continental era en donde estaba, hasta hace muy poco tiempo, completamente proscrito que se llevara ante la jurisdicción penal un proceso contra la propia persona jurídica. Esta era sancionada exclusivamente por el Derecho administrativo sancionador y, solo ocasionalmente, era posible que dentro de un proceso penal llevado contra una persona natural se le impusieran algunas medidas restrictivas a la persona jurídica.

Dentro de esta tradición jurídica, la discusión en torno a la aceptación o no de una responsabilidad penal de las personas jurídicas ha girado en torno a tres temas fundamentales: el primero es sobre la capacidad de acción que tienen las empresas y sí, de ser así, son capaces de actuar con sentido penal; el segundo, y quizás el más importante y sobre el cual la discusión alcanza su punto más álgido, ha sido si las entidades colectivas tienen capacidad de culpabilidad que les permita ser objeto de sanciones penales, lo cual nos conduce obligatoriamente al tercer punto de discusión, referido al sentido de la pena que tendría que ser impuesta a una persona jurídica.

Si bien dentro de la doctrina ya existen algunos trabajos que aportan elementos de discusión, a continuación presentaremos este texto que, esperamos, sirva dentro de toda la discusión nacional. 


\section{FUNDAMENTOS PARA PROMOVER UNA RESPONSABILIDAD PENAL DE LAS PERSONAS JURÍDICAS}

\section{La protección de bienes jurídicos como punto de partida y su incidencia en la criminalidad de empresa}

Debemos precisar que, para efectos de fundamentar una responsabilidad penal de las personas jurídicas, se tendrá como fundamento la posición de Roxin (2013) en cuanto a que el fin del Derecho penal es la protección de bienes jurídicos, junto con el aporte que hace BERND SHÜNEMANN (2007), en torno a que el bien jurídico es, a la vez, un elemento inmanente al sistema y un concepto crítico con el sistema; lo que termina por convertirlo en el punto de confluencia, es decir, ya no solo es un límite al ejercicio punitivo, sino también un elemento para la interpretación del mismo.

Ahora, observando lo anterior desde una perspectiva de política criminal, es claro que, como bien lo afirma SHÜNEMANN, la necesidad de protección de bienes jurídicos se presenta como urgente en una sociedad en la que las empresas adquieren cada vez más relevancia y sus actos traen consecuencias ya no solo en los ámbitos económico e industrial, sino también en aspectos esenciales para los individuos en lo que a su desarrollo en sociedad implica. Esto, en palabras de SHÜNEMANN (1982), se traduciría en un "estado de necesidad del bien jurídico".

Ciertamente, a medida que crece la interacción económica propiciada por la inmensa e imparable evolución de la globalización, las grandes empresas y poderes económicos toman una importancia trascendental e insoslayable en todo el ámbito jurídico (CAlDas Botero, 2010). En efecto, el desarrollo de sus actividades ha dejado de ser un tema exclusivo del Derecho privado, para empezar a tener relevancia en el Derecho penal, puesto que no solo crean enormes riesgos de lesión a bienes jurídicos, sino que en muchas ocasiones terminan lesionándolos de manera concreta (ídem). Es así como van adquiriendo una gran relevancia, más aún cuando los Estados deciden promover una cultura del libre comercio a través de tratados internacionales ${ }^{2}$.

Esa situación de riesgo para los bienes jurídicos ha tenido en Colombia una particular incidencia por las especiales características de violencia que se desarrolla en el país desde hace varias décadas, y cuya reducción apenas se plantea como una esperanza a futuro. Ejemplo claro al respecto es el caso de la explotación de carbón en el departamento del Cesar. En un informe emitido en junio de 2014, por la ONG

1 Planteado también en un trabajo publicado el año 2003 en el libro de memorias sobre las Jornadas internacionales de Derecho penal realizadas por la universidad Externado de Colombia (SHÜNEMANN, 2003).

2 Tal y como lo ha venido haciendo Colombia. 
de derechos humanos Pax Christi $(2014)^{3}$, se pone de presente cómo grandes y reconocidas empresas carboníferas han apoyado a grupos paramilitares con la entrega de recursos financieros y materiales e, incluso, con la entrega de información estratégica. Todo sin importar que los grupos paramilitares se hallen catalogados como organizaciones terroristas.

Esta situación apunta a la configuración del delito de “Administración de recursos relacionados con actividades terroristas", contemplado en el artículo 345 de nuestro Código Penal, pues deriva en una lesión o un atentado de manera concreta al bien jurídico tutelado llamado "Seguridad Pública". Ahora, como el hecho de darles dinero y bienes a grupos paramilitares para que permitan las operaciones carboníferas de la empresa es un comportamiento realizado por la propia empresa con el ánimo de obtener mayores beneficios en sus actividades de exportación minera, se evidencia la necesidad de regular situaciones claras de lesión o atentados a intereses protegidos a través de un Derecho penal que incluya a las empresas. Si se parte del concepto de que la finalidad que se predica de las normas penales es proteger aquellas situaciones requeridas para un libre desarrollo del ser humano, así como también de los presupuestos sociales en los cuales este se desarrolla (RoXIN, 2013), no se encuentra razón alguna para dejarla inalcanzada, por el hecho de dejar un vacío de punibilidad (con su consecuente generación de impunidad) a actores sociales sin cuya existencia o intervención tales conductas no se producirían. Esto es, por la simple renuencia de negar una responsabilidad penal de las personas jurídicas.

Como se observa, no se trata de simples conductas que afectan tan solo de manera tangencial al ser humano. Todo lo contrario, son hechos que atentan de una manera insoportable y urgente los intereses necesarios para una convivencia social armónica. Esta situación no se reduce a la lesión de intereses particulares sino que, también, pone de presente la importancia de tutelar los discutidos bienes jurídicos colectivos, los cuales son considerados como nuevas categorías de protección encaminados ya no solo a la protección del sujeto en su esfera netamente individual sino también en la defensa de determinados presupuestos sociales requeridos para su pleno y tranquilo desarrollo (Henao Cardona y Balmaceda Hoyos, 2006). De no protegerlos, el Estado social y democrático de Derecho al que pertenecemos, en el que los principios de libertad y solidaridad irradian a todo el ordenamiento, se dedicaría únicamente a proteger meras actitudes individuales que, si no se les reconoce su relevancia social, no tendrían sentido alguno. Los bienes jurídicos son completamente esenciales por su importante trascendencia para la realización de las necesidades básicas de los individuos (ídem).

Los delitos ecológicos son una buena muestra de lo dicho. Si bien el Derecho penal pretende proteger, a través de la amenaza de la imposición de una pena, la vida del

3 Cuya sede se encuentra en Holanda. 
individuo (Roxin, 2013), no completaría su función si no se protegiera, además, el ambiente necesario para su desarrollo completo y digno. De ahí que la penalización por lesionar al medio ambiente, teniéndolo como bien jurídico colectivo, es absolutamente válida como complemento de la protección de bienes jurídicos individuales. Ahora, teniendo claro que las personas jurídicas son las que con mayor capacidad de daño llegan a vulnerar los bienes jurídicos colectivos que pretende tutelar el legislador, se comprende con mayor razón la necesidad de una ampliación de la punibilidad hacia estas.

Sin embargo, si bien es cierto que la teoría del bien jurídico ${ }^{4}$ sirve como fundamento legislativo en la extensión de la responsabilidad penal a las personas jurídicas, solamente lo es en cuanto tiene una relación directa con el desarrollo de la política criminal. Pero, en lo que respecta a la libertad de configuración ostentada por el legislador, esta solo encuentra justificación con un vínculo jurídico obligatorio en la Carta Política, como límite máximo al que debe obedecer el poder legislativo (Roxin, 2013), con lo cual es posible encontrar un equilibrio entre la implantación de la política criminal predicada y los límites intrínsecos de esta (HERnÁNDEZ, 2010).

Es en este punto donde se halla otra justificación para la implementación de un sistema de responsabilidad penal para las personas jurídicas. En efecto, en Colombia la Corte Constitucional ya se pronunció al respecto, al emitir un concepto totalmente favorable a esa ampliación del ámbito de regulación penal. Mediante la Sentencia C-320 de 1998, evaluó la constitucionalidad de lo que fuera la Ley 491 de 1999 que versaba sobre la protección al medio ambiente, concluyendo que este tipo de responsabilidad era perfectamente compatible con los lineamientos constitucionales emanados de la Ley Fundamental ${ }^{5}$.

En las consideraciones de dicha sentencia se observa con claridad cómo la Corte tuvo en cuenta la necesidad de protección de bienes jurídicos esenciales para la sociedad, al tiempo que afirmaba que la decisión le pertenecía completamente al poder legislativo, pues se enmarcaba dentro su libertad de configuración. En concreto, dijo la Corte en relación con la necesidad de proteger bienes jurídicos:

La ley penal brinda la máxima protección jurídica a bienes valiosos para la persona humana y la vida social. La traducción de esta defensa en sanciones penales, tiene un propósito tanto comunicativo como disuasorio. Cuando la acción prohibida por la norma penal es susceptible de ser realizada por un ente -y no solamente por una persona natural-, limitar a esta última la imputabilidad

4 Entiéndase la teoría en su sentido amplio: tanto bienes jurídicos individuales como bienes jurídicos colectivos.

5 Para un estudio más profundo sobre la constitucionalidad de la responsabilidad penal de las personas jurídicas en Colombia, véase Darío BAZZAni Montoya (2001). 
penal reduce el ámbito de protección acotado por la norma. En el campo de ciertos delitos la extensión de la imputabilidad penal a las personas jurídicas, resulta necesaria para proteger debidamente a la sociedad.

Del planeamiento de la Corte en cita se observa que el llamado estado de necesidad del bien jurídico (SHÜNEMANN, 2003) encuentra un asidero constitucional, pues el ámbito de protección de la norma procura evitar lesiones o puestas en peligro que, en realidad, pueden ser cometidas por entes colectivos.

Ahora, en lo que respecta a la autonomía legislativa, expresó la Corte:

Es un asunto, por tanto, que se libra dentro del marco de la Carta a la libertad de configuración normativa del legislador y concretamente a su política sancionadora donde reina exclusivamente la persona natural -muchas veces ejecutora ciega de los designios corporativos provenientes de sus centros hegemónicos- para ocuparse directamente de los focos de poder que se refugian en la autonomía reconocida por la ley y en los medios que esta pone a su disposición para atentar de manera grave contra los más altos valores y bienes sociales.

Resulta así claro que hay suficientes razones de política criminal para que, con el establecimiento de un verdadero Derecho penal para las personas jurídicas, se protejan bienes jurídicos colectivos esenciales para la convivencia en sociedad, que en últimas terminan protegiendo también bienes jurídicos individuales. Sin embargo, estos argumentos aún no son suficientes, pues dentro del análisis de su fundamentación todavía queda por descartar los argumentos que sostienen que el Derecho administrativo sancionador podría cumplir a cabalidad esa función.

En torno al tema, deberá abordarse el principio de ultima ratio, que permitirá observar la viabilidad en Colombia de un sistema de responsabilidad penal de las personas jurídicas.

\section{El Derecho penal como ultima ratio para la protección de bienes jurídicos. Aspectos sobre el Derecho administrativo sancionador}

El Estado, en el ejercicio de sus funciones democráticas, puede hacer uso de su poder sancionatorio en diversos ámbitos. A este poder se le conoce tradicionalmente como el ius puniendi, y es una potestad que no solo es ejercida por los jueces, sino también por toda la administración $(\mathrm{C}-853,2005)^{6}$, puesto que es necesario tener

6 En este mismo sentido se pueden ver, entre otras, las sentencias C-506 de 2002, C-406 de 2004, C-860 de 2006 . 
medidas correctivas y sancionatorias con el ánimo de proteger el orden público y el funcionamiento correcto de las esferas sociales en las que el Estado interviene, así como para protegerse a sí mismo de graves alteraciones que puedan llegar a afectarlo (RAMíREZ TORRADO, 2007).

Dentro de todas las categorías en las que se ejerce dicha potestad ${ }^{7}$, solo nos interesa para este trabajo resaltar dos de ellas: el Derecho penal y el Derecho administrativo sancionador. Esto, ya que una de las más grandes discusiones que se presentan en torno a la implantación de una responsabilidad penal de las personas jurídicas es si esta es, en realidad, necesaria. Dicho de otro modo, si ciertamente cumple las funciones que se predican de ella o si, por el contrario, existen otros mecanismos más eficaces y menos drásticos que puedan cumplir cabalmente con los objetivos que se proponen. En palabras aún más concretas, ¿es el Derecho penal la mejor solución para sancionar las lesiones a bienes jurídicos protegidos cometidas por entes colectivos o resulta suficiente dejar estas situaciones en el campo del Derecho administrativo sancionador? Solo si esta pregunta es respondida afirmativamente, se puede seguir con el análisis de los demás puntos en discusión sobre el tema; de otro modo, las subsiguientes disertaciones serán estériles.

Establecido como punto de partida el hecho de que el Derecho penal pretende proteger bienes jurídicos, deberá verificarse si esa función se compagina con el principio rector de la ultima ratio, apartando así al Derecho administrativo sancionador.

Partiendo del hecho de que el ius puniendi ejercido por el Estado es uno solo, pero que tiene diversos alcances (RAMÍREZ TORRADO, 2007), es necesario establecer en qué aspectos se diferencian estos, para obtener un punto de partida sobre el cual evaluar la situación. Al respecto, la doctrina mayoritaria ha dicho en reiteradas ocasiones que el aspecto principal que permite distinguir el uno del otro no es más que un aspecto cuantitativo, esto es, una diferencia simplemente formal (CALDAS BOTERO, 2010). Tanto el Derecho administrativo sancionador como el Derecho penal se encargan de proteger bienes jurídicos, ya sean individuales o colectivos, solo que las lesiones que se dejan para el Derecho penal son aquellas cuya gravedad es mayor; mientras que el Derecho administrativo sancionador se ocupa de lesiones más leves ${ }^{8}$. Por lo tanto, solo aquellas lesiones que sean consideradas verdaderamente insoportables, trasgresoras de los intereses más básicos del individuo o de la sociedad en la cual este se desarrolla, serán aquellas a las cuales sea legítimo imponer una sanción penal con todo el rigor y consecuencias que un proceso de esta naturaleza representa.

7 Derecho penal, Derecho administrativo sancionador, régimen disciplinario, régimen de policía, etc.

8 En este punto, Luisa CALdAs Botero (2010), MARÍA RAmírez Torrado (2007), Silvina BaCigaluPo (2001), e incluso Fernando PERdomo Torres ( 2009), aun cuando, para él, siguiendo la postura de JAKOBS, la finalidad del Derecho penal está en mantener la vigencia de la norma. 
Ahora, dentro de aquellas razones que se considera que legitiman la intervención penal se encuentra la función predicada de la prevención de delitos, protegiendo de esta forma bienes jurídicos (URBANO MARTínEZ, 2002), dando lugar al desarrollo de los principios de subsidiariedad y fragmentariedad.

En torno al principio de subsidiariedad, se dice que el Derecho penal no aspira a proteger absolutamente todos los bienes jurídicos que puedan existir en una sociedad que es, por demás, multicultural; sino que defenderá solo aquellos sin cuya observancia sea imposible el adecuado desarrollo de la libertad del individuo y de la comunidad en la que se encuentra. En otras palabras, protege situaciones fundamentales para la convivencia social (ídem). Es así como se apartan del Derecho penal aquellas situaciones en las que, tratándose de entidades colectivas, se considera posible resolver a través del Derecho administrativo ${ }^{9}$, tales serían, por ejemplo, simples incumplimientos de contratos, ya sea con el público en general o con la administración, o aspectos de publicidad engañosa, entre muchos otros.

Lo que sí no puede ser dejado de lado son aquellas conductas cometidas por empresas que, por su incidencia de carácter fundamental, se convierten en esenciales para la sociedad en general. Ejemplo de ello, además de muchos delitos económicos importantísimos, son la captación masiva y habitual de dinero, la desviación de fondos pensionales o, incluso, la usurpación de marcas y patentes, los cuales implican un grave atentado contra el orden económico y social. También se encuentran delitos contra el medio ambiente, sobre los que no existe duda acerca de su importancia, como ya se anotó. Igualmente, las figuras del lavado de activos y la financiación al terrorismo, sobre las que nadie duda, porque financiar organizaciones terroristas no solo propicia situaciones de riesgo para la vida de los asociados, sino que pone en peligro la propia supervivencia de la comunidad en concreto e, incluso, la del Estado mismo. De igual forma, el blanqueo de capitales, que muchas veces provienen del narcotráfico, no solo termina por patrocinar el tráfico ilegal de estupefacientes, sino que sus consecuencias llegan a poner en riesgo la estabilidad de todo el sistema económico nacional. Tales conductas pueden ser cometidas ${ }^{10}$ por empresas de toda índole, muchas de ellas verdaderas corporaciones transnacionales de tal entidad que el Estado no tiene más alternativa que recurrir al uso de su potestad sancionatoria más severa y drástica: el Derecho penal.

El principio de subsidiariedad, con el que se pretende diferenciar aquellas conductas que deben ser llevadas al Derecho penal y las que, por el contrario, deben perma-

9 Sobre esto, confróntese la interesante posición de SHÜnEMANN (2007), para quien la relación del Derecho penal con el Derecho administrativo, e incluso con el Derecho civil, no es de subsidiariedad sino de complementariedad.

10 Conductas que no pueden ser reducidas a la simple entrega material del dinero por parte de la persona física, como se verá en el acápite siguiente. 
necer en el campo del Derecho administrativo sancionador, se observa cumplido a cabalidad en las situaciones mencionadas, pues la intervención de personas jurídicas es verdaderamente determinante.

$\mathrm{Y}$, en lo que respecta al principio de fragmentariedad, podemos decir que si bien el Derecho penal pretende proteger aquellos bienes jurídicos esenciales para la sociedad, no lo hace frente a cualquier clase de lesión o puesta en peligro, por cuanto el Derecho penal solo actúa cuando la lesión al bien jurídico es considerada como grave socialmente. Esto implica que "la protección que suministra el Derecho penal a los bienes jurídicos también está sometida a una selección adicional que tiene en cuenta la gravedad de la lesión inferida por el actor, pues aquellas lesiones o puestas en peligro que son socialmente intrascendentes no le interesan al Derecho penal" (URBANO MarTíNeZ, 2002).

Acá no vale la pena imponer sanciones a las empresas que, eventualmente, lesionen algún bien jurídico de manera inocua. Las situaciones que deben estar cobijadas por el ámbito de protección del Derecho penal son aquellas que, ya teniendo claros los bienes jurídicos relevantes de acuerdo con el principio de subsidiariedad, pongan en verdadero peligro o lesionen de manera suficientemente grave el bienestar social $\mathrm{o}$ individual.

Por ello, a manera de ejemplo, vale la pena volver sobre dos delitos referidos con anterioridad: el lavado de activos y la financiación al terrorismo. En el lavado de activos tenemos que el legislador pretende, principalmente, proteger el orden económico (BAZZANI MONTOYA, 2003), en atención a que permitir el ingreso de dineros para cuya obtención se saltan las barreras de la legalidad, haciendo que la competencia en el mercado sea absolutamente desigual, puede alterar de manera grave el correcto funcionamiento de la economía que el Estado debe garantizar (ídem). Por otro lado, con la sanción penal de la financiación del terrorismo, si bien la seguridad pública es considerada en un primer momento como el bien jurídico a proteger, por las importantes consecuencias que se derivan de las actuaciones terroristas, se está protegiendo, además, el correcto funcionamiento de casi todo el ordenamiento jurídico (Cruz Bolívar, 2003). Y, como ya se mencionó, tales conductas pueden ser cometidas por personas jurídicas, por lo cual la capacidad de daño o de lesión de bienes jurídicos individuales y colectivos se amplía de una forma considerable, dada la mayor capacidad que las grandes empresas tienen para el desarrollo de ese tipo de comportamientos, tanto en lo económico como en lo operativo.

Como se ve, las lesiones o atentados contra los bienes jurídicos mencionados, citados apenas a manera de ejemplo, tienen una importancia indiscutible que resulta de mayor entidad y preocupación cuando se trata de una verdadera comisión por entidades colectivas, por lo que la protección fragmentaria del Derecho penal se evidencia no solo legítima, sino, además, necesaria. 
En tales condiciones, resulta indispensable para el Estado hacer uso del ius puniendi jurídico-penal, como una de las herramientas más eficientes llamadas a responder adecuadamente, con el fin de controlar y sancionar a las personas jurídicas por sus propias actuaciones, cuando las mismas alcanzan el umbral de la ilicitud penal, esto es, porque desarrollan comportamientos contemplados como delito en nuestra legislación penal.

\section{CAPACIDAD DE ACCIÓN DE LAS PERSONAS JURÍDICAS}

Si bien de lo hasta ahora expuesto se considera que desde el punto de vista de la política criminal las razones que fundamentan una verdadera imposición de responsabilidad penal de las personas jurídicas resultan satisfactoriamente determinantes, resta por analizar los dos aspectos considerados los más importantes sobre los cuales ha versado la discusión dogmática: la capacidad de acción y la capacidad de culpabilidad predicada de los entes colectivos. Nos referiremos inicialmente al primer punto solo para después tratar lo relacionado con la culpabilidad empresarial.

Debe recordarse que la capacidad de acción de las personas jurídicas y su responsabilidad penal no es algo novedoso para la doctrina. En efecto, el delito cometido por el ente colectivo fue conocido en la Edad Media y se mantuvo hasta la mitad del siglo XVIII en gran parte de Europa (FERRARA, 1929) ${ }^{11}$. Sin embargo, si bien siempre hubo algunos contradictores, para FERRARA ${ }^{12}$ no fue sino hasta cuando SAVIGNY dijo que un sujeto artificial y sin voluntad no tenía la capacidad de realizar actos ilícitos ni mucho menos estar sometido a alguna clase de responsabilidad y pena, que la discusión acabó enterrando de forma definitiva las posibilidades de que las corporaciones respondieran penalmente por sus actos. Para los seguidores de esta tendencia, tales actos recaían sobre las personas naturales que actuaban por la organización y no podían ser reflejados sobre una institución creada por la ley (ídem). Por supuesto, para FERRARA este campo de irresponsabilidad resultaba muy perjudicial a las necesidades del comercio, por lo que siempre se opuso a que las cosas fueran así. Afirmó que resultaba muy contradictorio hacer responsables a los entes colectivos por las relaciones contractuales que materialmente eran realizadas por los órganos que actúan por la empresa, puesto que "si la culpa contractual tiene por efecto modificar la obligación existente, y aun hacer una nueva, la causa de esta transformación es siempre el dolo o la culpa, y si se parte del axioma de que esto no puede nunca inficionar a la persona jurídica el resarcimiento admitido, deviene una incongruencia" (ídem).

Decía también el autor en comento que, a pesar de que se estableció una pequeña clase de responsabilidad basada en la teoría de la ficción, esta no fue suficiente ya que si la

11 En este mismo sentido, Silvina Bacigalupo (2001).

12 Véase en sentido contrario, Percy García CAVEro (2005). 
persona jurídica es absolutamente incapaz y esta incapacidad se supera artificialmente por lo que hacen sus representantes, se debe entender que sus actos la vinculan tanto en lo lícito como en lo ilícito, y por lo tanto debe soportar sus consecuencias en los dos ámbitos (ídem). Además, estando muy cerca de LISZT, consideraba que el hecho de que una persona jurídica pueda cometer actos ilícitos es incuestionable "desde el momento en que puede realizar actos jurídicos: es el reverso de la medalla" (ídem).

Como se ve, estas cuestiones, si bien en principio nos pueden parecer relativamente nuevas, no han sido del todo ajenas a la doctrina. Sin embargo, con la evolución del método dogmático en el Derecho penal, las posibilidades de imponer una pena (en todo su sentido) a una organización se fueron cerrando cada vez más, y no fue sino hasta finales del siglo pasado que esa discusión resurgió decididamente (BACIGALUPO, 2001). No obstante, y a pesar de todo el desarrollo que la discusión ha tenido, la base antropocéntrica sobre la cual se erigieron las categorías dogmáticas hace que aún haya fuertes contradictores. Esto se debe, principalmente, al punto desde el cual se analiza la cuestión. Si para discutir sobre la capacidad de acción de las personas jurídicas se sigue partiendo del hecho de que acción es solo un comportamiento humano que inicia un curso causal, según lo predicado por el causalismo, o si, en otro sentido, se parte del finalismo, en cuanto considera la orientación final de la acción como su base fundamental, seguirá siendo imposible desarrollar una plena responsabilidad para entes colectivos; en otras palabras, el fundamento natural y antropocéntrico conducen al fracaso de todo intento doctrinal de imputar responsabilidad jurídico penal a los entes colectivos (REYES, 2008).

Todo esto puede llegar a superarse si, desde un comienzo, se parte de una observación social y normativa de lo que se considera persona. Así, siendo el Derecho penal uno de los instrumentos democráticos en los cuales se refleja la idea de sociedad, es posible entender el delito como una simple construcción social encaminada a la protección de los valores e intereses necesarios para la vida en comunidad (ídem). La sociedad en determinado contexto histórico ve la necesidad de tipificar como delitos unas específicas conductas que lesionan bienes jurídicos. De aquí que las personas deban ser consideradas en su concepción social y, después, en su aspecto normativo. Solo así se podrán entender sus acciones desde la órbita jurídico-penal.

En tal sentido, por persona debe entenderse todo aquel que, siendo portador de derechos y obligaciones, orienta sus acciones bajo esos supuestos normativos, dada su consideración como sujeto activo en la sociedad (ídem). Si esto es así, fácil es decir que las personas jurídicas son personas capaces en todo su sentido dentro del ordenamiento jurídico colombiano. Ya la Corte Constitucional reconoció en las personas jurídicas plena capacidad para ser titulares tanto de derechos como de obligaciones. En efecto, en la Sentencia C-510 de 1997 sostiene que: "Toda persona jurídica tiene derecho a que su conducta se investigue o se juzgue en los estrados o se verifique administrativamente por las entidades estatales con miras a establecer cualquier clase de responsabilidad". Esa providencia permite concluir que esas personas tienen obli- 
gaciones normativas que cumplir y que, por lo tanto, son capaces de desobedecer, lo que hace posible exigirles responsabilidad. Como es obvio, también se les reconocen derechos propios para la exigencia de responsabilidad, como son la presunción de inocencia y la garantía del debido proceso (C-510, 1997).

En todo caso, el hecho de que se ostente la calidad de persona ${ }^{13}$ no significa que lo sea en todos los ámbitos, tal y como lo afirma JAKOBS (2003) en una de sus críticas. Por sus propias características, frente a la personas humana o individual, siempre habrá limitaciones impuestas normativamente o surgidas de su propia naturaleza de acuerdo con la calidad propia de cada una y reconociendo sus particulares características para el ejercicio de actos jurídicos o ser destinatario de regulaciones normativas. En efecto, si bien un niño no puede votar ni celebrar contratos por su cuenta, no significa que por carecer de esas capacidades legales deje de ser persona para el ordenamiento jurídico y que, por ende, pierda los derechos y obligaciones que, se supone, recaen sobre su cabeza (REYES, 2008). Lo relevante aquí es saber si las personas jurídicas, como sujetos de derechos y obligaciones, son capaces de realizar acciones que interactúen con el Derecho penal.

Para esto, debemos entender como acción social toda actuación cuyas consecuencias superan la esfera íntima de quien la desarrolla, para interactuar con otras personas (FERRARI, 2012) y, de esta forma, intervenir en la sociedad.

Entendiendo que el Derecho penal es un reflejo de la sociedad que regula, se comparte la posición del profesor YESID REYES (2008), en cuanto afirma que "lo que realmente hace el Derecho penal es valorar negativamente una conducta en cuanto ella tenga un significado social contrario a unos deberes de conducta establecidos como forma de protección de bienes jurídicos". Así, lo relevante para el Derecho penal no es la actuación en su puro sentido natural, sino en su sentido social y, con mayor razón, cuando con esta se atenta contra intereses considerados como necesarios para la vida en sociedad. Es por esto que una empresa que contamina el medio ambiente es valorada de forma negativa, sin tener en cuenta a la persona física que realizó materialmente la conducta (REYES, 2008). La "acción compleja" (ídem) de contaminar un río o de talar un bosque sin autorización es lo que se considera relevante socialmente y, por ende, es susceptible de valoración negativa.

13 Además de la idea de persona, CARLos Gómez-JARA DíEz (2008) ha desarrollado el concepto de la "Ciudadanía empresarial" como fundamento teórico de su llamado "Modelo constructivista de autorresponsabilidad penal empresarial", y, sobre este, ha ideado la noción del ciudadano corporativo fiel al Derecho, con sus vertientes formal y material. Sobre la vertiente formal, el concepto de ciudadano corporativo fiel al Derecho se refiere a que las empresas tienen la obligación de institucionalizar una cultura empresarial de fidelidad al Derecho. Sobre la vertiente material se refiere a que las empresas tienen la posibilidad de participar en los asuntos públicos (GómEZ-JARA DíEZ, 2008). Sin embargo consideramos que las vicisitudes que representa otorgarle, ya no una personalidad jurídica a las empresas, sino una "ciudadanía", tiene consecuencias demasiado amplias que vendrían a alterar de manera significativa todo el ordenamiento jurídico. 
Por cierto, esas acciones complejas de las que habla el profesor YESID REYES no son extrañas para el Derecho penal. Ejemplo de ello es el caso de la banda que roba un banco y, por lo cual, a todos sus integrantes se les condena por hurto agravado, aun cuando materialmente solo uno fue el que materialmente extrajo el dinero de la caja fuerte, mientras los otros amenazaban a los guardias y vigilaban la llegada de las autoridades (ídem); el Derecho penal ya reconoce la división del trabajo y la importancia del aporte en casos de autoría y participación. Empero, cuando se trata de organizaciones complejas, como lo son las personas jurídicas, es necesario ir un paso más adelante.

En los casos de participación delictiva, la diferenciación e identificación plena de las voluntades individuales no requiere mucho trabajo. Cuando se trata de una banda criminal no se configura una persona independiente con interacción jurídico-social propia; en tal caso, es fácil hacer desaparecer la banda con la simple aprehensión de los integrantes físicos que la componen, sin que exista mayor peligro de una subsistencia permanente y estable. Todas las actuaciones realizadas por los integrantes pueden ser interpretadas con facilidad como acciones propias de las personas individuales, sin que por ello se afecte la responsabilidad cuando estas se suman en un objetivo común. Pero esta situación claramente no se presenta cuando de una persona jurídica se trata. Ello porque el desarrollo de las actividades empresariales, las decisiones que se toman, y su respectiva ejecución, se realizan por los órganos que la representan o dirigen, como parte de una organización que se rige por normas claras y precisas, buscando un interés principalmente económico, desplegando una acción de carácter institucional (PALACIOS MEJía, 2003). No se trata de una simple banda criminal, pues, por el contrario, cada uno actúa en su propio interés y las valoraciones individuales aún son determinables, mientras que los entes colectivos con personalidad jurídica son verdaderas organizaciones en las cuales la actitud individual se confunde o, mejor, es consumida por la actitud de la empresa.

Es en este sentido que consideramos la acción de la persona jurídica como una acción organizacional compleja. Acá no se trata de la simple suma de los miembros para considerarla un ente con personalidad autónoma: es organizacional, puesto que parte de un complejo proceso de formación jurídica, cuyo cumplimiento es lo que le permite adquirir relevancia normativa propia, para así convertirse en una organización independiente. Y es compleja puesto que se separa de la visión estrictamente material de la conducta, en la cual se observan aisladamente las actuaciones realizadas, para entenderla como parte de un todo (REYES, 2008).

Ahora, para que una actuación pueda ser considerada como acción organizacional compleja imputable a la persona jurídica debe, en primer lugar, ser realizada por una persona que tenga capacidad de vincularla; en otras palabras, esta debe estar relacionada de alguna forma con el ente colectivo. En estos casos no se observa solo el plano formal de vinculación (que puede ser un contrato), sino también aquellas situaciones en las cuales una persona ostenta con suficiente credibilidad una repre- 
sentación de hecho de la empresa. Y, en segundo lugar, las actuaciones realizadas deben tener como fin la obtención de un beneficio para la empresa, el cual puede ser directo o indirecto. Con esta concepción se dejan de lado las acciones realizadas por representantes de la empresa que terminan por beneficiar únicamente a quien las realiza. Este elemento es esencial para que se pueda entender socialmente la capacidad de acción de las personas jurídicas.

Como para el Derecho penal son relevantes las acciones consideradas más allá de su simple concepción natural, esto es, en cuanto tienen un contenido social, es fácil asimilar la capacidad de acción de las personas jurídicas, entendiéndolas como acciones organizacionales complejas. Así, retomando el ejemplo del delito de financiación al terrorismo por parte de empresas carboníferas (PAX, 2014), es fácil encontrar la procedencia de su aplicación en Colombia, pues no se debe mirar solo a quien le entregó físicamente el dinero a los paramilitares, porque la relevancia social de la conducta no se reduce a ese simple hecho. Lo importante para el Derecho penal es que la empresa, a través de una persona con capacidad de representarla válidamente, decidió apoyar económicamente a un grupo considerado terrorista, con el fin de beneficiarse a sí misma, en aras de garantizar una mayor explotación del carbón. Esto es, de su propósito económico, propósito bajo el cual actúa el órgano de la empresa que materializa la conducta. En ese contexto, el Derecho penal colombiano bien puede entrar a tener en cuenta a la persona jurídica como capaz de realizar una acción organizacional compleja, que desemboque en una verdadera responsabilidad penal.

Lo expuesto permite concluir que la persona jurídica realiza acciones organizacionales complejas con pleno sentido social que, cuando traen como consecuencia la lesión de bienes jurídicos protegidos, evidencia plena capacidad para interactuar dentro de la jurisdicción penal y, por lo mismo, de la posibilidad de ser considerada como un verdadero autor de un delito.

\section{CAPACIDAD DE CULPABILIDAD DE LAS PERSONAS JURÍDICAS}

Tal vez el problema que más dificultades presenta, y en el cual se funda la esencia de la posición de los contradictores al reconocimiento de la responsabilidad penal de las personas jurídicas, es el de la capacidad de culpabilidad de las mismas. De hecho, el tema en cuestión ha sido tradicionalmente el escollo principal y la fuente más grande de discusión de la cual se han nutrido los principales argumentos de aquellos que se oponen al establecimiento de este tipo de responsabilidad. Posición entendible, puesto que el actual Derecho penal ha sido erigido bajo la base del principio de culpabilidad, como baremo principal de su existencia y aplicación, pues no se comprende un Derecho penal contemporáneo sin que se entienda que en él está implícito el principio de culpabilidad. El Derecho penal de hoy es, entonces, un Derecho penal de culpabilidad (BERnAL CuÉLLAR, 2011). 
Al respecto, el concepto de culpabilidad en el Derecho penal se ha entendido en dos aspectos distintos: el primero, lo trata como principio básico de la teoría penal y, el segundo, como la última categoría dogmática de la conducta punible que se debe evaluar después del juicio de tipicidad y de antijuridicidad, antes de proceder a la imposición de pena (VELÁZQUEZ, 2009).

Las críticas que se fundamentan contra de la responsabilidad penal empresarial a partir del concepto de culpabilidad han versado, indistintamente, sobre los dos aspectos referidos. Por esta razón, se tratará el punto de la culpabilidad examinando los dos ámbitos mencionados; pero haciendo una especial relevancia al segundo, esto es, al juicio de culpabilidad como categoría dogmática que se puede predicar a la propia empresa.

Con respecto a la culpabilidad como principio del Derecho penal, si bien con algunas diferencias, la doctrina en general reconoce que contiene dos aspectos fundamentales (BERNAL CuÉllar, 2011): el primero de ellos trata sobre la personalidad de la sanción. Esto es que el delito solo puede serle atribuido a la persona que lo comete y, por tanto, la sanción debe serle impuesta únicamente a quien realizó la conducta punible, sin que se pueda extender la sanción penal hacia aquella persona que no ha cometido o no ha participado en la comisión del delito.

El segundo aspecto, considerado el más importante como principio, es la prohibición de una responsabilidad objetiva. Conforme al mismo, se excluye la responsabilidad por el mero resultado y, sobre esta base, se eleva el concepto de culpabilidad a categoría dogmática ${ }^{14}$.

El aspecto relativo a la personalidad de las penas es desarrollo de una larga tradición criminal, que en sus inicios hacía responsable a una o varias personas por la pertenencia a un grupo. Bajo ese pensamiento se desarrollaban la venganza de los clanes o la criminalización por la pertenencia a una familia, para los llamados delitos de sangre. Posteriormente, se evolucionó con la denominada "ley del talión" (PINEDA AGUILAR, 2012). Este desarrollo se dio a través de los siglos; sin embargo, no fue sino hasta el siglo XIX cuando se acuñó por primera vez el concepto culpabilidad (VELÁZQUEZ, 1993) y, con ello, los ámbitos que emanan de él. Así, la culpabilidad como criterio para establecer la personalidad de la sanción fue la salida a la responsabilidad colectiva de entonces, la cual, años después, alcanzaría un punto álgido con el advenimiento de los regímenes nazi y fascista, que repercutieron en toda Europa. La responsabilidad

14 Para Fernando VelázQuez (2009), la culpabilidad como principio incluye, además de los dos mencionados, el hecho de que la pena no puede superar el límite de la culpabilidad, y esta se debe mirar desde los niveles de responsabilidad que van desde la culpa hasta el dolo, pasando por la preterintención. Adicionalmente, dice que este principio trae la idea de una proporcionalidad como "pauta surgida del postulado de igualdad para tasar la pena en concreto". 
personal es, pues, una respuesta contraria a criterios de penalización por la simple pertinencia a un grupo determinado (VELÁZQUEZ, 2009).

Acorde con la postura en cita, una de las críticas más fuertes que se le hace a la imposición de un sistema de responsabilidad de los entes colectivos, es que al implantarlo se estaría sancionando a personas que nada tuvieron que ver con la comisión del delito, por el simple hecho de pertenecer a la sociedad, lo que se considera violatorio del principio de culpabilidad, pues conlleva a imponer dos sanciones diferentes: una a la persona física y otra a la persona moral, por la comisión de un solo hecho (VAN WeEZEL, 2011). Sin embargo, esto no es del todo cierto, por varias razones.

En primer lugar, porque dentro del ordenamiento jurídico es indiscutible que la persona jurídica y la persona natural que encarna al órgano de aquella son dos personas totalmente diferentes. Entendiendo que en el marco del sistema normativo colombiano, persona es todo aquel sujeto sobre el cual recaen derechos y obligaciones (REYES, 2008), es perfectamente posible sostener dicha afirmación. Para justificarla no solo basta remitirse, fuera de la penal, a las diversas ramas del Derecho en las cuales se les da plena personalidad a los entes colectivos, otorgándoles además de derechos, con sus respectivas medidas de protección, obligaciones que se les pueden exigir de diversas formas. Circunstancia que también se puede apreciar directamente en el ordenamiento constitucional, respecto a lo cual, como se mencionó en antes, la Corte Constitucional ya se pronunció, al afirmar que de la persona jurídica es absolutamente posible predicar derechos y obligaciones, cuya base proviene directamente de la Ley Fundamental (C-510, 1997).

Segundo, porque respecto del argumento de que se sanciona a la persona jurídica por un hecho ajeno, esto es, por la conducta cometida por el órgano, entendido este como la persona que lo ostenta o ejerce la función, debemos insistir que se trata de dos acciones completamente diferentes. Ya dijimos que para el Derecho penal no son extrañas las acciones complejas y que, tratándose de acciones realizadas por empresas, estas deben ser entendidas como acciones organizacionales complejas. Por ello, una cosa es la acción física de entregar dinero a un funcionario público para la redirección fraudulenta de un contrato y otra, muy distinta, la acción cometida por la empresa que viola sus deberes de supervisión y vigilancia haciendo que, a causa de una organización defectuosa dentro de sí, termine motivando o promoviendo a su representante para que soborne a un servidor del Estado por razón del mismo contrato.

Ahora, respecto de los que dicen que con esto se estaría castigando también a los socios o accionistas de la empresa quienes no tienen nada que ver con la comisión del delito, debemos decir que esto tampoco ha de entenderse así. Ciertamente, sabemos que la empresa es mucho más que la suma de sus integrantes y los aportes que se le hacen, razón por la cual se predica y se entiende que, una vez constituida, forma una persona diferente a los accionistas. Por lo tanto, no se estaría castigando penalmente al accionista, sin importar si es mayoritario o minoritario. Lo que se estaría sancio- 
nando es el aporte que se hizo para la formación de la empresa, el cual ha adquirido autonomía al convertirse en parte de la persona jurídica.

Por tanto, a todas luces se evidencia bastante diferente la situación respecto a la idea de que se castiga o está castigando al aportante, pues dicha circunstancia estaría recogida en el marco del riesgo propio de la inversión que se hace dentro del sistema económico a través de una persona moral, pues claro es que las consecuencias perjudiciales soportadas por el accionista tampoco violan el principio de personalidad de la pena. Similar conclusión podría predicarse cuando se impone una sanción administrativa a la persona jurídica que, en la generalidad de los casos, termina afectando los intereses del accionista o aportante de la misma.

Además, porque respecto del Derecho penal individual nadie argumenta que, con la imposición de una pena al padre de familia que lava activos, se esté sancionando también a la esposa o a los hijos que dependían económicamente de él, porque la privación de su libertad le impide cumplir con esas obligaciones.

Bajo los presupuestos señalados, la argumentada violación del principio de culpabilidad, en cuanto refiere al aspecto de personalidad de las penas, no cuenta con sustento suficiente para descartar una responsabilidad penal de las personas jurídicas.

Nos queda entonces por establecer si, atribuyendo responsabilidad penal a las personas jurídicas, se estaría hablando de una responsabilidad penal objetiva o, en otras palabras, si de lo que se trata es de sancionar a la organización por la simple constatación de que se han lesionado bienes jurídicos, es decir, predicando una responsabilidad netamente objetiva. Para ello se tomará como fundamento lo establecido en la Constitución y su desarrollo reiterado en diversas ocasiones por parte de nuestra Corte Constitucional.

Según el artículo 29 de nuestra Constitución Nacional, las reglas del debido proceso deben ser observadas en cualquier tipo de actuación sancionatoria que se desarrolle $\mathrm{y}$, consecuente con ese principio, toda persona debe ser considerada inocente hasta tanto no se haya demostrado plenamente su culpabilidad. Con base en esos postulados, la Corte Constitucional ha concluido, en reiteradas ocasiones, que el principio de culpabilidad rige para toda clase de actividad sancionadora del Estado: llámese Derecho administrativo sancionador o responsabilidad penal propiamente dicha. La Corte lo afirma sin dubitaciones, cuando señala que "[e]stá proscrita toda forma de responsabilidad objetiva en materia sancionadora" (C-597, 1996). Por ende, hace indiscutible que en Colombia está absolutamente proscrita cualquier clase de responsabilidad penal carente de un vínculo subjetivo entre el sujeto y la conducta punible ${ }^{15}$.

15 Entre muchas otras sentencias, se pueden citar: C-948 de 2002, C-616 de 2002 y C-233 de 2002. 
Pero es que no solo se encuentra vigente el principio de culpabilidad dentro del sistema administrativo sancionador: también hacen parte del mismo los principios de legalidad, tipicidad, prescripción, proporcionalidad y non bis in ídem (C-948, 2002). Por tanto, como ya se afirmó, lo que permite diferenciar las sanciones administrativas de las sanciones penales es la intensidad o la gravedad con la que son lesionados intereses colectivos o individuales, considerados necesarios para la vida en sociedad.

Entonces, si el principio de culpabilidad ya se encuentra vigente también en el Derecho administrativo sancionador, y este no se viola con la imposición de sanciones a las personas jurídicas, no se entiende como este mismo principio se considera violado a la hora de predicar la imposición de una responsabilidad penal para las mismas (CALDAS BOTERO, 2010) ${ }^{16}$. Si la prohibición de responsabilidad objetiva hace parte de nuestro ordenamiento jurídico, ¿cómo es que sí resulta aceptable que se les impongan sanciones a las empresas por lesión a bienes jurídicos en el desarrollo de su actividad por fuera de la jurisdicción penal y no dentro de esta? Esta cuestión es omitida por los críticos del tema.

Como se ve, la culpabilidad entendida como principio general del Derecho penal en sus dos aspectos principales (la responsabilidad personal de las penas y la prohibición de responsabilidad objetiva) no constituye fundamento real para oponerse a la implantación de una responsabilidad penal de los entes colectivos, toda vez que, primero, la sanción que se impone es a dos personas diferentes por dos acciones distintas y, segundo, aunque desde la misma Constitución de 1991 se proscribió de nuestro ordenamiento la responsabilidad objetiva, esto no impide que las personas jurídicas sean sancionadas en el marco de un proceso administrativo; por tanto, tampoco se violaría con la imposición a las mismas de una sanción dentro de la jurisdicción penal.

Teniendo esto claro, debe examinarse lo relacionado con el principio de culpabilidad como categoría dogmática, con el fin de establecer si las personas jurídicas son capaces o no de esta.

La culpabilidad como categoría dogmática ha sido, a su vez, solución y problema para todo el Derecho penal. Si bien permitió avanzar en la teoría del delito hacia un Derecho penal mucho más garantista y sólido, también ha sido objeto de bastantes y reiteradas críticas provenientes desde todos los sectores que, o han tratado de modificarla con el fin de buscarle un fundamento considerado mucho más lógico, o han llegado incluso a proponer que sea reemplazado ${ }^{17}$. Sin embargo, y muy a pesar de todos los críticos, la doctrina mayoritaria se ha inclinado por la idea de mantener a la culpabilidad como sustento de la teoría del delito. Tenemos entonces que el juicio

16 En este mismo sentido, MARÍA RAMírEz ToRRADo (2007).

17 Sobre la evolución del concepto de culpabilidad, puede verse a HANS-HEINRICH JeSCHECK (2003). En la doctrina nacional: Fernando Velázquez (1993) y Miguel Córdoba Angulo (1989). 
de culpabilidad sigue siendo imprescindible para el establecimiento de una responsabilidad penal.

Sobre la definición de culpabilidad se pueden encontrar diversas posturas que, a pesar de que no son completamente iguales, sí coinciden en los puntos más generales. JESCHECK (2003), por ejemplo, afirma que la culpabilidad "es el fundamento para poder responsabilizar personalmente al autor por la acción típica y antijurídica que cometido mediante una pena estatal". Por su parte, el profesor MiguEL CóRDOBA ANGUlo (2002) dice que la culpabilidad "puede definirse, desde una perspectiva meramente formal, como aquel conjunto de condiciones necesarias que permiten justificar la imposición de una pena a un sujeto que ha realizado una conducta típica y antijurídica". Podemos decir que la culpabilidad es el último análisis que se hace en el juicio de responsabilidad a una persona que ha realizado una acción típica y antijurídica, para la imposición de una pena. En este orden de ideas, se puede argumentar que la culpabilidad es, entonces, el fundamento de la pena, siendo útil en dos ámbitos: como requisito de punibilidad y como criterio para la determinación de la pena (JESCHECK, 2003). La culpabilidad es la razón y el límite de la pena que se debe imponer (CóRDOBA ANGUlO, 1989).

A pesar de que en la definición general parece haber un relativo consenso, la doctrina no ha podido establecer cuál es la razón o la base de la culpabilidad, dando lugar a que se desarrollen varias teorías que examinaremos muy resumidamente, analizando sus posibilidades dentro de la responsabilidad penal empresarial.

La primera de ellas es la que trata la culpabilidad desde un ámbito psicológico. Esta entiende que la culpabilidad es la simple relación mental o psíquica que existe entre la acción realizada y el autor que la despliega. Bajo esta óptica es que el dolo y la culpa son temas que se tratan en sede de culpabilidad y no de tipicidad (CóRDOBA Angulo, 2002). Se detiene en el estado mental del autor (JESCHECK, 2003). Dicha teoría debe ser descartada para las personas morales por la elemental razón de que sobre estas no puede sustentarse un concepto psicológico o psíquico.

Posteriormente, descartada esta teoría por los problemas que presentaba para explicar casos de culpa sin representación (CóRdOBA ANGULO, 2002), se desarrolló una concepción más normativa, pero sin dejar de lado los elementos psicológicos. Es precisamente la concepción psicológica-normativa de la culpabilidad la que incluyó por primera vez la base de la libertad de voluntad como fundamento de la culpabilidad. Con este sustento se dice que era posible hacerle un juicio de reproche al autor, por haber cometido una conducta típica y antijurídica cuando le era posible actuar de otro modo. Sin embargo, no se abandonó del todo la relación subjetiva de la persona con el hecho, por lo que el dolo y la culpa siguieron haciendo parte de la misma (VELÁZQUEZ, 1993), lo que nos conduce a rechazarla para las personas jurídicas, por las mismas razones que se rechazó la anterior, esto es, porque partir de un concepto psíquico resulta metodológicamente incorrecto. 
En la evolución del concepto, se plantea la postura puramente normativista, que descarta el vínculo mental existente entre el autor y la acción realizada, esto es, el dolo y la culpa, para basarse únicamente en la libertad de configuración del comportamiento como fundamento. Así, la culpabilidad sigue siendo un juicio de valor ético y moral que se le hace a la persona que, pudiendo actuar de otra manera, decide realizar una conducta típica y antijurídica (ídem). En otras palabras, porque lesiona bienes jurídicos conscientemente. Teoría que, se podría decir, es la que se encuentra aún vigente dentro de la doctrina, y es la que se observa en el desarrollo e interpretación de nuestro ordenamiento. Y es con esta base que deben abordarse los problemas en torno al análisis de nuestro tema.

Es que si culpabilidad significa que una persona puede decidirse en contra del Derecho a partir de una autodeterminación libre, responsable y moral (HIRSCH, 2003), jamás podrá decirse que un ente colectivo es responsable penalmente. No solo por lo indemostrable que resulta en sí el criterio del libre albedrío como tal, tanto para las empresas como para las personas físicas (CÓRDOBA ANGULO, 1989), sino por lo erróneo que sería intentar encajar a una persona moral dentro del concepto de conciencia. Ya lo dijo JAKOBS (2003) cuando, para negar la punibilidad de asociaciones de personas, sostuvo que estas carecen de autoconciencia que les permita tomar posición respecto de la norma.

Pero, igual que con el problema de la capacidad de acción, partir de conceptos elaborados únicamente para seres humanos, con el fin de rechazar un Derecho penal para no humanos no solo es equivocado, sino también metodológicamente incorrecto, pues siempre traerá como conclusión la negación de la responsabilidad penal de las personas jurídicas.

Adicionalmente, porque establecer que el juicio de culpabilidad es un reproche ético o moral también resulta exagerado, no solo para las personas jurídicas, sino también para las personas naturales. De ser la imposición de una pena un reproche moral o ético, afirma VELÁzQUEZ, se habría cambiado todo el Derecho penal por una jurisdicción puramente moralista (VELÁZQUEZ, 2009). De esta forma, consideramos que acá tampoco cabe lo dicho por HiRSCH (2003), en cuanto afirma que la culpabilidad empresarial ya se entiende socialmente al afirmar que una u otra empresa contaminó un río, o que la ética y la moral no le son extrañas a los entes colectivos, puesto que a estas se les reconoce el derecho al honor y al buen nombre. Pensamos que las bases para una verdadera culpabilidad en el marco de un Derecho penal para las empresas no pueden surgir de un reproche que se reduce al simple uso de un lenguaje coloquial. Por esto, resulta evidente la necesidad de crear un nuevo concepto de culpabilidad que parta de bases diferentes (ya no del aspecto psicológico, moral o consciente), para concretar esta nueva evolución del Derecho penal hacia uno dedicado exclusivamente a la actividad empresarial. Como ya se dijo, máxime cuando las razones de política-criminal hacen de esto un imperativo inexorable. 
Para establecer un concepto de culpabilidad propia de las personas jurídicas, como hemos afirmado, debemos partir del concepto social y normativo de persona. Bajo esta premisa, si se afirma que persona es aquel sujeto del cual se predican derechos y obligaciones (REYES, 2008), significa que, al igual que la capacidad de acción, la culpabilidad empresarial debe ser entendida socialmente, y no de una manera aislada. Con mucha más razón, si se parte (como nosotros lo hacemos) de la idea de que el fin del Derecho penal es la protección de bienes jurídicos. Con esto, el Derecho penal se presenta como mecanismo de control social que admite además la idea de motivación, la prevención general y la prevención especial como fines buscados a través de la imposición de una pena (CóRdobA Angulo, 1989). En otras palabras, se considera que la culpabilidad tiene que ser entendida en la forma que lo plantea el profesor CóRDOBA ANGULO, esto es, como un fenómeno social y no individual (ídem).

Así, si "la función de motivación es un proceso de interacción social" (ídem), con la amenaza de la imposición de una pena se pretende conminar a las personas jurídicas para que se organicen de tal forma que prevengan la lesión de bienes jurídicos. Esto no se puede hacer entendiendo que estas se reducen a la simple suma de sus miembros. Dentro del ordenamiento jurídico se les da la posibilidad de interactuar dentro de todo el sistema económico, no solo entre ellas, sino también entre estas y personas físicas, lo cual hace que su interés para evitar lesionar intereses protegidos se base completamente en un proceso de interacción social.

Si la culpabilidad está ligada al concepto de persona como sujeto capaz de cometer acciones que tienen relevancia penal, puesto que provienen de un sujeto sobre el cual recaen obligaciones jurídicas, normativas y sociales, el juicio de valor recae sobre la conducta de una persona social plenamente capaz. Entonces, se es responsable en el marco de un determinado contexto histórico, dentro de una sociedad establecida y bajo unas condiciones previas (VELÁZQUEZ, 2009) que conminan a la empresa a organizarse de tal forma que evite o, por lo menos, prevenga y facilite la investigación del hecho típico y antijurídico. Es con base en este concepto social de culpabilidad que nos remitimos al ya elaborado término de "defecto de organización" (TIEDEMANN, 1997).

Las personas jurídicas (como las individuales) deben seguir las pautas sociales y normativas impuestas, bajo las cuales tienen la obligación de disponer de una organización interna que contenga los riesgos que se derivan de su actuación. Con esto se ve cómo la función de motivación, o la amenaza de sanción, cumple acá un papel importante. A través de ella se alcanzan los objetivos de prevención general y prevención especial, previniendo a las empresas para que cumplan o desarrollen programas de organización que representen una verdadera lucha contra la comisión de delitos. La culpabilidad por defecto de organización hace que se le cuestione a la empresa el haber generado una lesión a bienes jurídicos por no haberse organizado de la manera correcta (Alarcón Arias y OSPINA PERdomo, 2012). 
Se trata de una culpabilidad que no contiene los mismos elementos predicados de la culpabilidad individual. Dichos elementos de la culpabilidad social son, conforme al profesor CóRDOBA: 1. El conocimiento de la antijuridicidad, esto es, el individuo tiene la posibilidad de conocer sus prohibiciones; 2 . La imputabilidad, que implica que el sujeto debe tener capacidades personales que le permitan motivarse, y 3. La exigibilidad de un comportamiento diferente, pues el individuo tiene que encontrarse en circunstancias que le permitan comportarse de acuerdo con el Derecho (CóRDOBA ANGUlo, 1989). Ya, para la persona jurídica los elementos que, consideramos, permitirían hacerle un juicio de culpabilidad basado en un defecto de organización serían: 1. La capacidad de organización que ostentan y 2. La obligación predicada de estas de contener los riesgos generados de su actividad.

La capacidad de organización que ostentan, pues se deriva de las prerrogativas otorgadas por el ordenamiento jurídico, el cual les ofrece amplias posibilidades de actuar. Al momento de su formación, cada forma organizativa adquiere diferentes opciones que le permitan completar el objeto por el cual se constituyen, y para lo cual deben satisfacer unos requisitos específicos. Por lo tanto, es por esa capacidad de interactuar con el mundo social que el Estado les da, que se les exigiría que respeten los intereses colectivos e individuales necesarios para que la comunidad en la cual desarrollan sus intereses pueda funcionar correctamente. Esto desembocaría en obligaciones de organización adecuadas, de tal forma que se contengan los riesgos generados de su actividad.

Con base en estos criterios se cambia el contenido de la culpabilidad individual, para transformarla en una culpabilidad empresarial compatible con su propia condición de persona jurídica.

La sociedad le reprocha a la persona moral, al ente colectivo que, teniendo la capacidad de organizarse de tal forma que no lesione bienes jurídicos puestos en riesgo al desarrollar su actividad, no se organiza correctamente, trayendo como consecuencia la vulneración de intereses colectivos. No se trata de un reproche ético, tampoco es un reproche moral: es un reproche social. Y no lo es por el simple uso del uso de la palabra culpa en el ambiente colectivo, sino que es social porque se hace a través de un proceso jurídico fundamentado en las normas legales y constitucionales que democráticamente han sido establecidas. Es la misma sociedad, a través de sus instrumentos democráticos, la que decide qué bienes jurídicos deben ser protegidos, y se castiga a la empresa porque, estando sometido a estos, no evita lesionarlos. Es decir, esta culpabilidad se entiende con unos determinados valores imperantes en un Estado democrático de Derecho (Córdoba Angulo, 1989).

Con todo, se debe dejar claro que con el desarrollo de esta teoría de la culpabilidad no se decide reemplazar todo el sistema penal. Quiere decir que las categorías dogmáticas que hacen parte de la teoría del delito individual siguen completamente vigentes para las personas físicas. La intención no es cambiar toda la tradición jurídica, sino hacerla 
más dinámica y que, de esa forma, responda a las necesidades político-criminales de la sociedad de hoy, en la cual las personas jurídicas adquirieron una relevancia sumamente importante que no puede ser desconocida y sí, por el contrario, debe ser ajustada acorde con las necesidades que el sistema jurídico y la sociedad lo exigen.

Así, se descarta la fuerte crítica que se le ha hecho a la responsabilidad penal de las personas jurídicas, en cuanto afirma que con esta se estaría acabando definitivamente el principio de culpabilidad (en sus dos concepciones) sobre el cual se ha erigido todo el Derecho penal.

Además, sabiendo que es un desarrollo que no está exento de críticas, no se aspira a que todas sean resueltas de manera satisfactoria para tomar la decisión de ampliar el Derecho penal. Si se espera que la teoría quede cerrada a todas las críticas para dar el paso a su consagración positiva, se debería también descartar el sistema penal individual, puesto que, aun y con todos los siglos que tiene de evolución, no ha logrado desarrollarse a la perfección.

\section{ESBOZO DE UNA PROPUESTA PARA EL CASO COLOMBIANO}

\section{Posible ámbito de aplicación}

Frente al ámbito de aplicación que podría llegar a adoptarse en Colombia, se considera que lo mejor sería establecer una responsabilidad penal que abarque a todas las personas jurídicas.

Pensamos que esto, además de facilitar enormemente el trabajo legislativo, es también de fácil implementación. No tendría sentido realizar una discriminación exhaustiva de todas las figuras organizativas, puesto que dificultaría su entendimiento y, posiblemente, podría llegar a generar vacíos legislativos de difícil solución, así como abrir una compuerta de salida para la constitución de empresas excluidas de ese tipo de responsabilidad, que podrían realizar los eventos punidos, sin que puedan ser perseguidas por el sistema.

En este orden de ideas, todas las personas jurídicas estarían cobijadas por el sistema de responsabilidad penal, ya sea que tengan o no ánimo de lucro, sean grandes, pequeñas o medianas empresas o, incluso, si son públicas o privadas. En consecuencia, todos los entes colectivos que ostenten personalidad jurídica podrían verse inmersos en un proceso de responsabilidad penal y ser destinatarios de las sanciones penales establecidas por comportamientos realizados por ellos.

Ahora, frente a los delitos respecto de los cuales podrían ser consideradas responsables, consideramos necesario proponer una ampliación del espectro de conductas punibles realizadas por personas jurídicas, respecto de los parámetros generales que 
se encuentran en la mayoría de ordenamientos del Derecho comparado. En estos, los tipos penales por los que responden las personas jurídicas son:

- Lavado de activos.

- Financiación al terrorismo.

- Cohecho de servidor público nacional o extranjero.

Sin embargo, y por las especiales características delincuenciales que ha padecido Colombia de grandes y organizadas bandas delincuenciales, el delito de financiación al terrorismo se debe redactar de tal forma que se incluya en él la financiación de bandas criminales o grupos ilegales, por parte de empresas. En efecto, los problemas de delincuencia organizada que azotan al país son indiscutibles, mucho más si se tiene en cuenta que los problemas derivados de las mismas (BACRIM) crece y se desarrolla cada vez con más fuerza ${ }^{18}$. Por lo tanto, si de garantizar la protección a bienes jurídicos se trata, la inclusión en este tipo de la financiación y apoyo a grupos criminales, por parte de la persona jurídica, se presenta como necesaria.

Adicionalmente, sería importante incluir también delitos contra el medio ambiente. Teniendo en cuenta que Colombia está dentro de los países a nivel mundial más ricos en biodiversidad y recursos naturales, la protección de los mismos tiene que ser una política primordial del Estado, que debe desarrollarse a través de todos los frentes posibles. En este contexto, es claro que la actividad empresarial e industrial es una de las fuentes de mayores lesiones al medio ambiente, lo que en Colombia tiene un argumento adicional, en cuanto a que las más grandes empresas se dedican a la actividad minera, con riesgos enormes e inocultables para el ambiente. Ahora, siendo la minería uno de los factores que más aporta al crecimiento del Producto Interno Bruto colombiano y siendo, además, desarrollada en mayor medida por grandes empresas trasnacionales cuyos sistemas de decisión internos son sumamente complejos, y que por su actividad tienen mayor tendencia a lesionar el ambiente, es imprescindible incluir también un tipo penal de esta categoría específica ${ }^{19}$.

Con estos delitos consideramos que se podría empezar a aplicar un Derecho penal para las empresas en Colombia, sin que, eventualmente y con el avance y desarrollo del mismo, se impida que se incluyan nuevos delitos a medida que la sociedad y la realidad lo vayan requiriendo.

Ahora bien, los requisitos que se deben cumplir para poder vincular a la persona jurídica con el delito deben ser, básicamente, los siguientes:

18 Sobre esto vale la pena mirar el análisis que hace ANGÉLICA ARIAS OrTIZ (2012) de la Fundación Nuevo Arco Iris en su revista Arcanos.

19 Respecto de la especial implicación que tiene la minería con el medio ambiente mirar el informe "Minería y medio ambiente en Colombia" elaborado por Fedesarrollo (2014). 
Primero, la conducta debe ser cometida materialmente por una persona natural dentro de la órbita de la persona jurídica. En concreto, nos referimos a todas las personas que tengan cargos o desarrollen actividades de dirección, administración y supervisión, ya sea que tengan una vinculación formal o lo hagan de hecho, bajo la autorización expresa o tácita de la propia empresa.

Segundo, igualmente, pueden ser realizadoras de la conducta punible aquellas personas subordinadas a las anteriores sobre las cuales estas ejerzan supervisión, dirección, control o vigilancia, que cometan alguno de los delitos mencionados, pues a través de la delegación es que los referidos en el numeral anterior terminan desarrollando su labor.

Tercero, la lesión al bien jurídico debe ser cometida con el ánimo de beneficiar a la persona jurídica, esto es, con la intención de que esta obtenga un provecho directo e inmediato. De esta forma, se dejan de lado las conductas que se cometieron usando a la persona jurídica, pero cuya finalidad nunca fue que esta consiguiera ganancia alguna, cuando, por el contrario, la persona natural buscaba un interés estrictamente personal o para un tercero.

El cuarto requisito, y tal vez el más relevante, es que el delito haya sido cometido debido a una organización interna defectuosa que permita, facilite, motive o, simplemente, no prevenga la comisión del delito. En otras palabras, que la empresa misma no haya cumplido con su obligación de contener los riesgos derivados de su actuación. Lo que resulta importante, puesto que es la organización defectuosa de la empresa la que hace que esta lesione los bienes jurídicos a los cuales se encuentra sometida en su obligación de respetar; esto es lo que permite realizar el juicio de reproche de carácter social que, como ya lo precisamos, es la base de la culpabilidad de la persona moral.

\section{Penas aplicables y algunas cuestiones adicionales}

Ya sobre el tema de las penas que se les podría imponer a las personas jurídicas, una vez hayan sido encontradas responsables penalmente, proponemos cuatro penas principales, a saber:

- La disolución o cancelación de la persona jurídica.

- La prohibición temporal o perpetua de celebrar actos y contratos con el Estado.

- La pérdida total o parcial de beneficios tributarios, o la prohibición absoluta de recibirlos durante un período determinado.

- Multa a favor del Estado.

El punto importante que se debe tener en cuenta es la situación especial que se presentaría en el momento en que a una persona jurídica de Derecho público proceda a 
imponerle la pena de disolución o cancelación. Podría pensarse en una sanción especial que consistiría en la toma de posesión por parte de un director especial nombrado judicialmente, que limite las actividades de los administradores que estuvieren en su momento, sin perjuicio de las sanciones penales o administrativas y disciplinarias que les corresponderían a estos.

Sobre el monto o la cuantía de la multa y el período de tiempo durante el cual exista la prohibición, ya sea de contratar con el Estado o de recibir exenciones tributarias, debemos decir que tales aspectos tienen que determinarse normativamente, atendiendo a la incidencia de la conducta, frente al orden jurídico y a los intereses sociales. Solo el legislador, una vez realizado un análisis y un debate democrático, puede establecer dichas reglas para su implementación.

En todo caso, consideramos que no estaría de más incluir la curatela empresarial, como medida de aseguramiento durante el transcurso del proceso. Si bien la propuesta de SHÜNEMANN se plantea más como solución al problema de la culpabilidad de las personas jurídicas, por lo que la propone como medida de seguridad, pensamos que termina siendo más útil su aplicación durante el proceso, pues el problema de la culpabilidad lo consideramos superado.

Esta es una figura que no es extraña para nuestro Derecho interno.

En efecto, ya las superintendencias tienen la posibilidad de ejercer, no solo vigilancia sobre las empresas, sino también un verdadero control e, incluso, el Estatuto Orgánico del Sistema Financiero trae la figura de la "Toma de posesión" ${ }^{20}$. Por lo tanto, lo único que habría que cambiar, por la precisa implementación de una responsabilidad penal de las personas jurídicas, es la jurisdicción bajo la cual se aplicaría. Si bien podría hacerse a través de una entidad administrativa, nada impide que la medida pueda adoptarse a través de los auxiliares de la justicia. De todas formas, este sería otro aspecto a definir por vía normativa.

Sin embargo, para que proceda la aplicación de la curatela como medida de aseguramiento sobre una entidad colectiva, pensamos que se debería observar algunos de los siguientes fines:

a. Evitar la obstrucción a la justicia y el entorpecimiento de la investigación.

b. Evitar que se continúen realizando las actividades que lesionaron los bienes jurídicos.

c. Garantizar los derechos de las víctimas a la reparación integral del daño.

20 Esta figura se encuentra consagrada en los artículos 114 y 115 del Decreto 663 de 1993, a los cuales se les adicionaron algunas causales con la expedición de la Ley 510 de 1999 y, posteriormente, sufrieron algunas modificaciones por la Ley 795 de 2003. 
Solo si se cumplen los anteriores requisitos, muy ligados a los ya existentes para la imposición de medida de aseguramiento para el caso del Derecho penal individual, podría procederse a aplicarla para la persona jurídica que se vea envuelta en un proceso penal.

Ya para terminar, pensamos también en la inclusión de causales de atenuación punitiva, pues pueden resultar tanto útiles como necesarias, en la persecución penal y la imposición de una pena. Tales podrían ser:

a. La reparación integral del daño, o impedir que este produzca mayores consecuencias negativas, antes de que se emita el sentido del fallo.

b. Colaboración con la justicia.

c. La adopción real y efectiva de un modelo de organización que prevenga la comisión de delitos antes de que se emita el sentido del fallo, cuyo cumplimiento estará sujeto a la aprobación de una entidad Estatal.

Si bien esto es tan solo un esbozo de un modelo de aplicación de la responsabilidad penal de las personas jurídicas para el Derecho colombiano, se debe dejar claro que las implicaciones del Derecho procesal son enormes y muy significativas, cuyo examen supera con creces el presente espacio, lo que implica que tienen que ser estudiadas mucho más a profundidad en el caso de que, eventualmente, se decida tomar la decisión de crear un Derecho penal para las personas jurídicas en el ordenamiento jurídico nacional.

\section{BIBLIOGRAFÍA}

Alarcón Arias, P. y Ospina Perdomo, J. M. (2012). “De la responsabilidad penal de las personas jurídicas”, en C. A. Gómez GonzÁlez y C. A. SuÁRez López, Estudios de Derecho penal II (pp. 47-84). Bogotá: Universidad Jorge Tadeo Lozano.

Corte Constitucional C-597, D-1229 (6 de noviembre de 1996).

Corte Constitucional. Sentencias C-510 y D-1635 (9 de octubre de 1997).

Corte Constitucional. Sentencia C-948 de 2002.

Corte Constitucional. Sentencias C-853, D-5637 (17 de agosto de 2005).

BACIGALUPO, S. (2001). La responsabilidad penal de las personas jurídicas. Buenos Aires: Hammurabi . 
Bazzani Montoya, D. (2003). “Del lavado de activos”, en J. C. Bernal CuÉllar, Lecciones de Derecho penal. Parte especial (pp. 41-53). Bogotá: Universidad Externado de Colombia.

Bernal Cuéllar, J. C. (2011). Lecciones de Derecho penal: Parte General. Bogotá: Universidad Externado de Colombia.

Caldas Botero, L.F. (2010). “Globalización y responsabilidad penal de las personas jurídicas. Especial referencia a las empresas", en J. E. BERNAL CUÉLLAR, XXXII Jornadas internacionales de Derecho penal. Derecho Penal económico y de la empresa (pp. 267-299). Bogotá: Universidad Externado de Colombia.

Córdoba Angulo, M. (1989). “Algunas reflexiones sobre el fundamento de la culpabilidad”, en Derecho penal y criminología, 75-93.

Córdoba Angulo, M. (2002). “Culpabilidad”, en J. C. Bernal Cuéllar, Lecciones de Derecho penal. Parte general (pp. 355-365). Bogotá : Universidad Externado de Colombia.

Cruz Bolívar, L. (2003). "Delitos contra la seguridad pública”, en J. C. Bernal CuÉllar, Lecciones de Derecho penal. Parte especial (pp. 435-482). Bogotá: Universidad Externado de Colombia.

FERrARA, F. (1929). Teoría de las personas jurídicas. Madrid: Reus.

FERRARI, V. (2012). Derecho y sociedad. Elementos de sociología del Derecho. Bogotá: Universidad Externado de Colombia.

GÓMEZ-JARA DÍEZ, C. (2008). "El modelo constructivista de autorresponsabilidad penal empresarial", en C. E. GóMEZ-JARA DíEZ, Modelos de autorresponsabilidad penal empresarial (pp. 141-194). Bogotá: Universidad Externado de Colombia.

Henao Cardona, L. F. y Balmaceda Hoyos, G. (2006). Introducción al Derecho penal de la sociedad postindustrial. Bogotá: Universidad del Rosario.

Hernández, H. (2010). "La introducción de la responsabilidad penal de las personas jurídicas en Chile", en Politica Criminal, 207-236.

HiRsch, H. J. (2003). "La cuestión de la responsabilidad penal de las asociaciones de personas”, en Anuario de Derecho Penal y Ciencias Penales, 1.099-1.124.

JAKOBS, G. (2003). “PPunibilidad de las personas jurídicas?”, en E. C. MonTEALEGRE LYNETT, El funcionalismo en Derecho penal: libro homenaje al profesor Günther Jakobs (pp. 327-347). Bogotá: Universidad Externado de Colombia. 
JESCHECK, H.-H. (2003). "Evolución del concepto de culpabilidad en Alemania y Austria”, en Ciencia Penal y Criminología, 01:1-01:19.

Palacios Mejía, J. M. (2003). "“Societas delinquere non potest” o "societas delinquere potest". Responsabilidad penal de las personas jurídicas", en A. CANCINO MoREno, Derecho penal y sistema acustorio en Iberoamérica (pp. 160-181). Bogotá: Universidad Externado de Colombia.

PAX (2014). The Dark Side of Coal.Paramilitary Violence in the Mining. Utrecht: Pax.

Pineda Aguilar, A. C. (2012). Responsabilidad penal de las personas jurídicas: ¿Viabilidad dentro del ordenamiento jurídico nacional? Bogotá: Pontificia Universidad Javeriana.

RAmírez Torrado, M. L. (diciembre de 2007). "Postura de la Corte Constitucional Colombiana en relación con el poder sancionador de la administración”, en Revista de Derecho, 300-328.

Reyes, Y. (2008). "La responsabilidad penal de las personas jurídicas”, en Derecho Penal Contempóraneo, 43-66.

Roxin, C. (2013). "El concepto de bien jurídico como instrumento de crítica legislativa sometido a examen”, en Ciencia Penal y Criminología, 01:1-01:27.

ShünEmAnN, B. (1982). "Cuestiones básicas de dógmatica jurídico-penal y de política criminal acerca de la criminalidad de empresa", en Crónicas Extranjeras, 529-558.

Shünemann, B. (2003). “XXv Jornadas internacionales de Derecho penal”, en J. C. Bernal CuÉLlar. Bogotá: Universidad Externado de Colombia.

ShünEmann, B. (2007). ¡El Derecho penal es la ultima ratio para la protección de bienes jurídicos! Bogotá: Universidad Externado de Colombia.

Tiedemann, K. (1997). "Responsabilidad penal de las personas jurídicas”, en Anиario Derecho Penal, 97-126.

Urbano Martínez, J. J. (2002). “Concepto y función del Derecho penal”, en J. C. Bernal CuÉllar, Lecciones de Derecho penal. Parte general (pp. 13-25). Bogotá: Universidad Externado de Colombia.

VAN WeEZEL,A. (2011). “Contra la responsabilidad penal de las personas jurídicas”, en A. VAN WeEzel, Límites de la imputación penal: estudios 2000-2010. Bogotá: Universidad Externado de Colombia. 
VelázQuez, F. (1993). "La culpabilidad y el principio de culpabilidad", en Derecho y Ciencias Políticas, 283-310.

VelázQuez, F. (2009). Derecho penal. Parte general. Bogotá: COMlibros. 
